\title{
NARRATIVAS DE FORMAÇÃO DE PROFESSORES DE MATEMÁTICA SOBRE OS ESTÁGIOS SUPERVISIONADOS
}

- MARIA DAS GRAÇAS DOS SANTOS ABREU

Pontifícia Universidade Católica de Campinas

- MARIA AUXILIADORA BUENO DE ANDRADE MEGID

Pontifícia Universidade Católica de Campinas

ALESSANDRA RODRIGUES DE ALMEIDA

Pontifícia Universidade Católica de Campinas

RESUMO

Este artigo analisa experiências de formação de estudantes de um curso de licenciatura de Matemática de uma universidade privada do interior do Estado de São Paulo, que participaram de disciplinas relacionadas aos estágios docentes entre os anos de 2014 a 2018. São apresentadas e colocadas em discussão as orientações e estratégias de organização das disciplinas, bem como a execução e a realização das mesmas pelos envolvidos. Por estratégia reflexiva, foram adotadas as narrativas de vida e de formação, tanto no decorrer das disciplinas como na apresentação de um relatório final. Tais ações possibilitaram o processo reflexivo dos licenciandos sobre si e sobre a formação profissional. As narrativas, produzidas nesse percurso formativo, proporcionaram rememorar as experiências vivenciadas e também confrontar expectativas, sonhos e realidade, tanto profissional quanto da realidade educacional. Foi possivel identificar os efeitos dessa proposta de formação, como propulsora de reflexão sobre o percurso de aprendizagem docente, em que os participantes, ao narrarem suas experiências, encontraram possibilidades para uma ampliação da capacidade de conhecer-se e reconhecer-se na complexidade do ambiente formativo e educacional.

Palavras-chave: Formação de professores. Narrativas. Educação matemática. Estágio supervisionado.

ABSTRACT NARRATIVES OF MATHEMATICS TEACHER TRAINING ON SUPERVISED INTERNSHIPS

This article analyzes the experiences of student training within a Mathematics degree course of a private university in the country- 
side of the state of São Paulo that participated in disciplines related to the teaching stages between 2014 and 2018. The orientations and strategies of the organization of the disciplines are presented and discussed, as well as the execution and realization of the same by those involved. By reflective strategy, life and training narratives were adopted, both in the course of the subjects and in the presentation of a final report. These actions made possible the reflexive process about themselves and the professional formation. The narratives, produced in this formative course, allowed us to recall the lived experiences and also to confront expectations, dreams and reality, both professional and educational reality. It was possible to identify the effects of this training proposal as a propulsive reflection on the course of teacher learning, in which the participants, in narrating their experiences, found possibilities for an increase in the capacity to know oneself and to recognize oneself in the complexity of the formative environment and educational. Keywords: Teacher training. Narratives. Mathematical Education. Supervised internship.

\section{NARRATIVAS DE FORMACIÓN DE PROFESORES DE MATEMÁTICAS SOBRE LAS ETAPAS SUPERVISADAS}

Este artículo analiza experiencias de formación de los estudiantes del curso de licenciatura en Matemáticas de una universidad privada del interior del estado de São Paulo, que participaron de disciplinas relacionadas a las prácticas docentes entre los años 2014 a 2018. Se presentan y ponen en discusión las orientaciones y estrategias de organización de las asignaturas, así como la ejecución y realización de las mismas por los involucrados. Por estrategia reflexiva se adoptaron las narrativas de vida y de formación, tanto en el transcurso de las asignaturas como en la presentación de un informe final. Tales acciones posibilitaran el proceso reflexivo de los graduandos sobre sí y sobre la formación profesional. Las narrativas, producidas en ese itinerario formativo, proporcionaron rememorar las experiencias vivenciadas y también confrontar expectativas, sueños y realidad, tanto profesional como de la realidad educativa. Fue posible identificar los efectos de esta propuesta de formación como propulsora de reflexión sobre el recorrido de aprendizaje docente en el que los participantes, al narrar sus experiencias, encontraron posibilidades para una ampliación de la capacidad de conocerse y reconocerse en la complejidad del ambiente formativo y educativo.

Palabras Clave: Formación de profesores. Narrativas. Educación Matemática. Etapa Supervisada. 


\section{Introdução}

Nas disciplinas de Metodologia do ensino de Matemática e Estágio Supervisionado, que compõem a grade curricular do curso de licenciatura em Matemática de uma universidade privada do interior do Estado de São Paulo, procuramos desenvolver um trabalho que buscou contemplar os movimentos que estudam a formação de professores de Matemática e que buscaram romper com a lógica estrutural do pensamento vigente de que a área em que se situa essa disciplina é "dura", dificil e rígida, o que pode sugerir que o profissional de matemática não seja sensivel aos problemas educacionais.

Nossa proposta de trabalho com tais disciplinas alinha-se ao pensamento de que as atividades de ensino devem romper com a estrutura centrada no professor, e com a ideia de que a formação isolada proporciona a constituição de um profissional competente e com domínio dos conteúdos específicos da área, sem considerar os demais temas que envolvem a formação do futuro professor. Já sabemos que tal procedimento corrobora com a constituição de um profissional automatizado e sem interesse em compartilhar saberes e que permanece distante de iniciativas que permitam um conhecimento maior de si mesmo, como pessoa e como profissional docente, das tantas e diferentes experiências da sala de aula. Sobretudo, traz uma dificuldade em reconhecer como o aluno aprende e de que forma é possivel contribuir com seu aprendizado.

Nesse sentido, buscamos, ao longo de todo o curso, priorizar uma formação dialogada, com a utilização de estratégias que, com frequência, solicitam trabalhos em equipe, compartilhamento de saberes, e que mostram e colocam em discussão o trabalho realizado em sala de aula, conhecendo e discutindo a atuação de diferentes pares.
No elenco das disciplinas pedagógicas do curso de Licenciatura em Matemática, dentre as quais estão Metodologia do Ensino da Matemática e Estágio Supervisionado, buscamos desenvolver uma proposta pedagógica inovadora, que visa a integração com as demais áreas do conhecimento e a parceria entre a escola básica e a universidade, em uma perspectiva contextualizada que favoreça uma postura formativa e interdisciplinar, atendendo as demandas pessoais, formativas e sociais.

Entendemos que essas estratégias são essenciais para promover uma formação inicial que permita aos futuros professores construir caminhos formativos direcionados ao perfil do profissional que se pretende habilitar para o trabalho com a Matemática, nas escolas de ensino básico.

Compreendemos nessa relação dialógica tornar-se possivel avançar em conhecimento e com possibilidade de progressos para a formação pessoal e profissional docente do futuro professor de matemática. Um profissional com capacitação no trabalho da docência, com pleno domínio da matemática e das práticas ativas para sua interpretação, de maneira dinâmica e simples, para alunos da educação básica.

Para tanto, neste artigo, discutimos as estratégias de organização das disciplinas - a execução e a realização das mesmas pelos envolvidos (futuros professores e docentes das disciplinas), e a adoção da narrativa de vida e formação como um relatório final de trabalho que possibilita e dispara um processo reflexivo sobre si e sua formação profissional.

Discutimos o processo de formação e o potencial das narrativas, aqui entendidas, como um instrumento que favorece e potencializa o processo reflexivo da ação pedagógica e que também permite uma compreensão maior de 
si mesmo, revisitando um passado - remoto ou recente - na perspectiva de que haja condições de reformulá-lo, a partir de conhecimentos acadêmicos. Essa possibilidade de conhecimento, reflexão, criação e reformulação, oferecida pela produção de narrativas se orienta na mesma direção prevista por Oliveira (2011, p. 290), na compreensão de que a escrita de narrativas "como atividade que envolve interpretação e produção, assume um papel central em qualquer processo educativo, pois mobiliza conceitos e sistemas teóricos o que possibilita ao sujeito da ação formativa assumir o papel de protagonista". A partir do exposto, indicamos nossas concepções e trabalhos com as narrativas de formação na constituição do professor de matemática.

\section{As narrativas e a formação do professor}

Dentre os vários desafios da formação docente, destacamos o de formar profissionais que atendam as demandas velozes e emergentes do contexto educacional, de maneira mais focada nos aspectos da escola básica, por tratar-se do lócus de atuação dos profissionais do curso em questão.

As atualizações em cursos de formação inicial de professores estão sendo solicitadas por força de regulamentos legais acumulados nas últimas décadas, resultantes de debates e estudos sobre os professores, sua formação e atuação nas escolas. A partir dessa realidade, todos os cursos de licenciatura estão sendo ajustados às Diretrizes Curriculares Nacionais (DCN), estabelecidas pela Resolução no 2 , de 1o de julho de 2015, do Conselho Nacional de Educação (BRASIL, 2015).

Para além dos atuais desafios e obrigatoriedades de atualização, concordamos com Serrazina (2012, p. 267), no sentido de que "ser professor sempre foi uma profissão complexa".
Tal complexidade faz emergir necessidades de recursos e estratégias formativas que envolvam os licenciandos - futuros professores de forma a pensarem na sua formação como libertadora para o exercício do magistério. É imperativo fazer uso dos conhecimentos específicos que legitimam o exercício da profissão, mas, ao mesmo tempo, conhecer tais conteúdos de maneira reflexiva, projetada e amplificada, para que possam transformar esse conhecimento em algo a ser ensinado aos jovens da escola básica no contexto em que vivemos neste século.

O professor é um profissional que trabalha com o conhecimento, e, para tanto, precisa ter compromisso com a aprendizagem. Para Marcelo (2009), ser professor, nos dias de hoje, se configura em compreender que tanto os alunos como o conhecimento transformam-se e esse movimento de transformação acontece muito rapidamente, exigindo a formação de um professor que seja preparado para lidar com essas mudanças de maneira ágil, criativa e eficaz.

Concordamos com Imbernón (2011, p. 42), no sentido de que uma formação consistente necessita "dotar o professor de instrumentos intelectuais que sejam úteis ao conhecimento e à interpretação das situações complexas em que se situa". O autor indica também ser necessário envolver os docentes em atividades de formação comunitária, a fim de conferir à educação escolar uma dimensão que se situa na realidade social em que estão inseridos os alunos e no saber intelectual, mantendo uma estreita relação entre realidade e saber.

$\mathrm{Na}$ mesma direção, trazemos os apontamentos de Nóvoa (1995, p. 25), quando explica que "estar em formação implica um investimento pessoal, um trabalho livre e criativo sobre os percursos e os projetos próprios, com vista à construção de uma identidade, que é também uma identidade profissional". Para 
o autor, a formação se constrói por meio de uma reflexividade crítica sobre as práticas e na construção permanente da identidade pessoal. Dessa maneira, estar em formação implica um envolvimento da pessoa do professor e requer o desejo de formar-se.

A integração do sujeito como participante de seu processo de formação (NÓVOA, 2000), abriu caminho para estudos sobre as histórias de vida e os percursos profissionais dos professores. No Brasil, desde o início dos anos de 1990, despontam os estudos sobre o uso de narrativas de formação e aquelas que tomam "a experiência do sujeito adulto como fonte de conhecimento e de formação" (FREITAS; GHEDIN, 2015, p. 111).

Nas narrativas de formação, o passado, o presente e o futuro ganham um sentido temporal, que dimensiona a experiência do narrador. E na mesma dimensão destacada por Clandinin e Connelly (2011, p. 63):

[...] localizar as coisas no tempo é a forma de pensar sobre elas. Quando vemos um evento, pensamos sobre ele não como algo que aconteceu naquele momento, mas sim como uma expressão de algo acontecendo ao longo do tempo. Qualquer evento, ou coisa, tem um passado, um presente, da forma como aparece para nós, e um futuro implícito.

Buscamos, junto aos licenciandos, localizar elementos, em suas narrativas, que expressassem essa tridimensionalidade temporal, identificando as experiências que estruturam suas narrativas e que são rememoradas com o objetivo de arquitetar o presente ao mesmo tempo em que são usadas para projetar o futuro.

Abrahão (2011) defende que uma linearidade sequencial não precisa fazer parte do discurso narrativo, apoiando-se no fato de que a vida não tem essa natureza linear. O licenciando então, ao narrar suas experiências, quer sejam da sua trajetória escolar, ou das vivências nos estágios, pode rememorar episódios ao interpretar o presente, ao mesmo tempo que projeta suas ações futuras, sem que seja esperado que ele faça esse movimento de maneira linear, mas sim com interesse de que suas experiências evidenciem essa dinâmica.

Essa escrita sem linearidade é percebida também quando verificamos que muitos dos alunos do curso de matemática não têm experiência com a escrita e, não raro, a proposta de um trabalho narrativo gera desconforto e apreensão.

A ausência de um trabalho com a escrita nas aulas de matemática ainda é bastante recorrente e várias estratégias têm sido apresentadas e propostas para encorajar e incorporar essa rotina em diferentes niveis de ensino.

Freitas (2006, p. 276), sobre a escrita no processo de formação do professor, argumenta que:

A experiência formadora, mediada pela escrita discursiva, pode promover uma aprendizagem que articula, em diferentes contextos, tempos e interações, vários conhecimentos relativos ao saber ser, saber fazer e saber conduzir-se.

Concordando com esses autores, entendemos que, num nível local, buscamos contribuir com os futuros professores criando mecanismos que favoreçam o processo formativo. Nesse sentido, entendemos a narrativa como um instrumento facilitador e que propicia a configuração de um processo reflexivo sobre si e sobre a própria formação, exercendo forte mediação entre a formação acadêmica, a formação pessoal e o desenvolvimento profissional. Serve também de motivação para práticas futuras, de modo a minimizar angústias que podem surgir na atividade docente, possibilitando repensar ou compartilhar práticas docentes com o objetivo de estudá-las para a sua manutenção, adequação ou transformação.

A esse respeito, Reis (2008, p. 4) assim destaca: 
Através da construção de narrativas os professores reconstroem as suas próprias experiências de ensino e aprendizagem e os seus percursos de formação. Desta forma, explicitam os conhecimentos pedagógicos construídos através das suas experiências, permitindo a sua análise, discussão e eventual reformulação. A redacção de relatos sobre as suas experiências pedagógicas constitui, por si só, um forte processo de desenvolvimento pessoal e profissional ao desencadear, entre outros aspectos: a) o questionamento das suas competências e das suas acções; b) a tomada de consciência do que sabem e do que necessitam de aprender; c) o desejo de mudança; e d) o estabelecimento de compromisso e a definição de metas a atingir.

Ancoradas nessas perspectivas, temos nos aprofundado na compreensão e no uso das narrativas, como apresentaremos a seguir.

\section{Metodologia}

A estrutura das disciplinas Metodologia do Ensino da Matemática e Estágio Supervisionado, no curso de Licenciatura em Matemática em que atuamos, está organizada de maneira a privilegiar uma aproximação da prática pedagógica, com avanços significativos na perspectiva de trabalhos compartilhados com outros professores da área e com profissionais experientes que recebem os alunos quando da realização dos estágios supervisionados.

De acordo com as Diretrizes Curriculares Nacionais para as Licenciaturas, são determinadas 400 horas de carga horária mínima de estágios supervisionados. Assim, o curso de Licenciatura em Matemática oferece essas horas, distribuídas em três disciplinas semestrais de estágio supervisionado, a partir do quarto semestre, no segundo ano do curso. Os estágios supervisionados são acompanhados das disciplinas de Metodologia do Ensino de Matemática que acontecem nos mesmos semestres. Essas disciplinas têm por objetivo dar suporte teórico ao estudo de metodologias trabalha- das na introdução e no desenvolvimento dos diferentes conteúdos matemáticos. Busca ainda oferecer apoio no preparo de materiais e planos de aula para que os estagiários possam desenvolver as atividades de atuação planejadas junto aos professores da escola e da universidade.

As disciplinas que acontecem, nos 4으, 5으 e 6 o períodos (semestres) do curso têm por finalidade colocar o licenciando em contato com a realidade escolar, seu provável futuro local de trabalho, possibilitando uma visão abrangente do processo de formação profissional.

Utilizamos a estratégia de solicitar que cada estágio seja realizado em escolas de diferentes regiões do Município com o propósito de propiciar ao licenciando o contato com diferentes estruturas organizacionais, comunidades sociais e com alunos em diferentes fases do processo de aprendizagem. Ainda mais: proporcionar que diferentes equipes responsáveis pelo trabalho de gestão e organização educacional sejam observadas. Cabe salientar que tal proposta é sugerida, e que fica a critério do licenciando acatá-la ou não.

Os licenciandos são estimulados, desde o início do estágio, a assumir responsabilidades de acompanhamento do professor que o recebe e de auxiliar os alunos com intervenções que são previamente combinadas com ele. Podem ser orientações para os diferentes caminhos, na busca das soluções ou de conteúdos que precisam ser revisitados para realização das atividades. Os licenciandos em estágio são orientados também, e agora, pela docente universitária responsável pela disciplina de estágio, para que não se ocupem em dar respostas aos alunos, e sim em orientá-los sobre quais os caminhos/estratégias que podem escolher, chamando sempre a atenção para os conceitos que eles já possuem ou para cálculos recentes que tenham sido realizados e que podem ser acessados para diferentes atividades. 
São orientados também para que, sempre que possivel, comentem com os alunos sobre os conceitos, propriedades ou outros recursos que acessam, mesmo quando não têm clareza sobre eles. Essas ações caminham sempre em movimento crescente e são executadas com cuidado e acompanhadas, em aulas presenciais, pela docente universitária responsável pela disciplina de Estágio.

Todas as atividades são preparadas entre os profissionais da universidade e da escola, com interlocução realizada via aplicativo Whatsapp, ou por intermédio do licenciando, e estão orientadas pela concepção de que o trabalho está em construção, portanto, não se regulam por bases rígidas e podem ser reestruturadas, a depender da necessidade observada durante a sua realização. Tal possibilidade e/ou necessidade de mudança e adaptação é entendida, por nós, como algo que tende a desenvolver uma condição de autonomia no aluno que já está se preparando para o futuro exercício da profissão. Para além disso, pode proporcionar a configuração de um profissional com domínio sobre os conhecimentos específicos da disciplina que ministra. Bem por isso, precisa compreender a necessidade de constante adaptação e replanejamento de suas aulas, de acordo com as necessidades e a maturidade cognitiva de seus alunos. As atividades preparadas ganham valor à medida que atendem as especificidades dos grupos de alunos que vão sendo acompanhados pelos estagiários.

Ao final de cada atividade de estágio, de posse das anotações que são registradas em seus diários de estágio, os licenciandos são convidados a escrever uma narrativa com o objetivo de refletir sobre a experiência vivenciada, dando destaque aos episódios que entendem como formativos.

Essa escrita, portanto, constitui-se em momento reflexivo e, como bem traduz Oliveira
(2011), "numa aprendizagem experiencial", colocando o aluno diante e no interior de seu processo formativo a relatar as experiências e aprendizagens que entende como diferenciais em seu desenvolvimento profissional.

Considerando a organização curricular da licenciatura em matemática, o Estágio I está organizado de maneira a aproximar os alunos da escola básica e redirecionar o seu olhar que, até então, tinha um caráter mais passivo, que se manifestava com timidez, passando, agora, para um olhar observador e crítico, com as perspectivas de constituir o profissional professor.

Ao final do primeiro semestre da disciplina, o licenciando é orientado a escrever uma narrativa que contemple a sua trajetória escolar, destacando como entende essa mudança de lugar e a visão que ainda tem de aluno, para uma compreensão do papel do professor nesse processo. É proposto também que destaque como entende o trabalho, a vivência e a experiência que marcou sua trajetória de aprendizagem durante o ensino básico, sua decisão de tornar-se professor de Matemática, e como percebe sua inserção e envolvimento no processo de estágio, registrando as contribuições do curso, as próprias aprendizagens, e também as dúvidas e incertezas. Entendemos que a escrita das narrativas nessa perspectiva contribui para ampliar a compreensão sobre a sala de aula, o ensino, a aprendizagem, os alunos, com um olhar direcionado para o trabalho do professor, suas necessidades, sua postura, a condução dos diferentes momentos da aula. Os futuros professores são estimulados ainda a refletir como esses registros se encontram nas teorias estudadas sobre o que é ensinar e aprender.

No estágio II, e na disciplina de Metodologia II, os estudos e relatos das experiências permeiam as discussões sobre ser professor de Matemática. Na escola básica, o licenciando 
observa a realização ou não de atividades experimentais pelo professor que o recebe. Faz as primeiras avaliações das condições de realização das atividades de investigação matemática, auxilia o professor na produção e utilização de materiais previamente preparados e acompanha os grupos de alunos na execução da atividade.

Para o relatório final, é solicitada uma descrição das observações e da atuação na escola, das discussões apresentadas pelos grupos de alunos, em forma de narrativa. Esses registros podem ser diários ou semanais, e os licenciandos também são orientados a relatar de maneira reflexiva sobre a avaliação que fazem da proposta, de como foi executada, das adaptações realizadas e dos ajustes que entendem como promissores para novas realizações.

No estágio III, o licenciando, além dos momentos de observação e acompanhamento dos alunos, também desenvolve integralmente uma aula para a introdução de um conteúdo/ tema matemático, considerando o ano escolar e as orientações curriculares da escola. Essa intervenção também é discutida e organizada com o professor da escola parceira e preparada junto ao professor supervisor da universidade. Para esse estágio, é importante que o licenciando já tenha estabelecido um diálogo intenso com o professor da escola parceira para o planejamento da aula, com ênfase na discussão sobre o trabalho de atuação.

Para esta narrativa, que compõe relatório final do estágio, solicita-se um relato que privilegie o planejamento e a organização da aula e a atuação do licenciando. Ela deve ainda ser entendida como o eixo articulador da possibilidade de transformação das teorias sobre o que, para este graduando, significa ser professor de Matemática. Nesta narrativa, nosso foco de interesse são as experiências do último estágio realizado. A proposta ainda indica que sejam apresentadas, na narrativa, as reflexões sobre o processo formativo, pressupondo-se que já há também um conhecimento do processo autoformativo. O licenciando deve destacar a sua compreensão sobre a mudança de lugar - de aluno para professor - e de como essa percepção impacta o seu processo formativo.

A escrita da narrativa é compreendida como possibilidade do licenciando registrar o que sentiu e observou na escola, nos encontros com gestores, professores e estudantes, na sala de aula, e poder, pela escrita, iniciar a problematização de suas concepções sobre ser professor, e que estão sendo construídas a partir do ambiente onde atuará profissionalmente e reconstruídas a partir das memórias dos ambientes escolares que frequentou e, por fim, de entender esse processo como constitutivo da sua formação profissional.

As narrativas revelam o movimento cíclico e constante que caracteriza a formação do professor, sua visão dos espaços formativos e qual o seu papel enquanto professor em formação. Ficam evidenciados os processos de mudança que ocorrem nas dimensões previstas por Reis (2008, p. 4), quais sejam: “a) o questionamento das suas competências e das suas acções; b) a tomada de consciência do que sabem e do que necessitam de aprender; c) o desejo de mudança; e d) o estabelecimento de compromisso e a definição de metas a atingir". Tais processos demandam novas compreensões, posturas e adaptações ao processo formativo. Para evidenciar os movimentos percebidos nas narrativas, apresentamos alguns relatos seguidos de nossas análises.

\section{Ações e reflexões narradas e... refletidas}

Os trechos de narrativas apresentados na sequência, são centrados nas memórias e nos registros de dois licenciandos, provenientes 
das suas experiências escolares e das ações realizadas nos três estágios detalhados anteriormente. Os textos foram organizados considerando-se cada um dos estágios realizados.

Iniciamos trazendo as considerações dos licenciandos 1 e 2, na primeira disciplina que envolveu o estágio:

Falar sobre minha experiência de estágio é algo que me agrada muito, principalmente de perceber o quanto eu tenho mudado minhas concepções sobre alguns assuntos, os quais eu possuía um pré-conceito sem embasamento, mas agora eu consigo discutir e inclusive dar exemplos claros com base na minha experiência adquirida este ano em sala de aula. [licenciando 1, narrativa produzida em: 11/2016]

Todos esses alunos e amigos faziam os estágios enquanto eu, que trabalhava no setor privado o dia todo e ia para a universidade à noite. [...] esse processo de mudanças de concepções acontecia nas conversas durante o intervalo e inclusive durante as aulas, onde eles falavam das experiências vividas em sala de aula. [...] o mais interessante é que eles falavam com um espírito diferente, um espírito de querer mudar... de embarcar de vez nessa profissão, além, principalmente, de amarem a matemática assim como eu tinha me apaixonado perdidamente conforme as disciplinas iam aparecendo. [licenciando 1, narrativa produzida em: 11/2016]

Analisar criticamente minha própria trajetória e formação acadêmica, a partir das reflexões promovidas pelo meu primeiro contato com a realidade escolar e suas demandas. Ao ter contato com o ambiente escolar e todas as suas nuances, isto é, as paredes, as salas, a biblioteca, os uniformes, os alunos, os professores, os secretários e inspetores, as cozinheiras, os faxineiros, o sinal que marca o final da aula, o intervalo, os diários de classe, as reuniões, os pais e tudo mais que caracteriza e denota essa atmosfera da escola, pude ver e perceber nitidamente que tudo que havia sido ensinado a mim nesses três semestres em que estou na universidade ganhou sentido prático. [licenciando 2, narrativa produzida em: 11/2017]
Nas narrativas relativas ao primeiro estágio, observamos a presença de duas dimensões destacadas por Reis (2008), uma vez que os apontamentos dos alunos apresentam o questionamento das suas competências e das suas ações e também o desejo de mudança. Em seus registros, os licenciandos, ao cumprirem as exigências do Estágio Supervisionado, deparam-se com a dualidade de vivenciar situações diferentes num mesmo cenário, ou seja, a escola. Embora, seja o mesmo lugar, os papéis e as experiências são diferentes.

o licenciando 1 destaca que, assim como seus colegas, após vivenciar o estágio, a mudança aparece como uma palavra potente em seu processo formativo. Evidencia sua própria mudança numa perspectiva de tornar-se professor, enfatiza o desejo de querer mudar, observado inclusive nas conversas com os colegas de curso.

O licenciando 2, ao observar e detalhar em sua narrativa os espaços pessoais e profissionais da escola, estabelece uma relação entre a experiência vivida e a formação universitária, o que pode ser articulado à ideia de relações entre competências e ações destacada por Reis (2008). Nesse sentido, as narrativas permitem registar as memórias de lugares e concepções sobre o espaço educacional que traduzem lembranças e momentos de outro tempo. Dessa forma, estar no mesmo lugar, e por vezes encontrar os mesmos professores e gestores, provoca o dualismo tempo e lugar que marca espaços e papéis distintos.

Analisando agora os mesmos licenciandos no segundo estágio, passamos a considerar seus apontamentos quando são orientados a fazer uma descrição das observações e da própria atuação na escola. Destacamos alguns excertos das narrativas dos estudantes 1 e 2 sobre essa experiência.

Eu queria muito lecionar agora. 
Eu fiquei tão entusiasmado com a ideia do estágio que eu quis fazer os três estágios na escola onde me formei, inclusive com a mesma professora que me deu aula... [licenciando 1, narrativa produzida em: 06/2017]

No meu trabalho durante o dia eu não conseguia conter tanta ansiedade de anoitecer e de poder ir até a escola e ajudar os alunos a aprenderem mais e mais e esse fato aconteceu de uma maneira bem natural, pois sou apenas quatro anos mais velho que a média de idade dos alunos do terceiro ano do ensino médio. [licenciando 1, narrativa produzida em: 06/2017]

De repente, você se percebe inserido em uma realidade que ao mesmo tempo é nostálgica mas também desafiadora no sentido de que, ao ver o cotidiano da escola e principalmente dos professores, você é confrontado.

Digo isso porque vi de perto a realidade que me espera e me pergunto se estou aproveitando bem esse tempo de preparação. Vi a demanda [...] e a qualificação que se faz necessária. [licenciando 2, narrativa produzida em: 06/2018]

Sendo assim, como é possível que volte à sala de aula da universidade com a mesma mentalidade? Ora, transformado que fui pela experiência de estágio, olho para as disciplinas que já cursei e para as que ainda vou cursar a partir de uma nova perspectiva. Perspectiva essa que me lança a importância de reavaliar cada passo que dei até aqui e refletir sobre minha prática formadora, discente e por que não, docente. [licenciando 2, narrativa produzida em: 06/2018]

Na narrativa abre-se caminho para que o aluno (definitivamente protagonista da própria história) manifeste à sua maneira, ao seu modo, do seu jeito o próprio ponto de vista. Que forma melhor eu teria para conhecê-los? Conhecer a maneira deles de pensar e de se expressar? [licenciando 2, narrativa produzida em: 06/2018]

A narrativa do licenciando 2 traz elementos que podem ser associados à tomada da consciência do que sabem e do que necessitam aprender. Apresenta ainda sua reflexão sobre a própria formação (REIS, 2008) - se estou aproveitando bem esse tempo de pre- paração -, bem como marca a importância de refletir sobre sua "prática formadora", tanto como aluno quanto como professor. Nessa perspectiva, destaca ser necessária uma formação sólida, que se faz necessária para que o professor saiba lidar com os desafios e demandas da escola.

O licenciando evidencia ainda a importância da escrita da narrativa para o seu próprio processo formativo, mas também como uma possivel prática a ser utilizada enquanto professor, o que se relaciona com o estabelecimento de compromisso e a definição de metas a atingir, o que demanda novas compreensões, posturas e adaptações ao processo formativo (REIS, 2008).

Nas narrativas apresentadas, ao final do Estágio II, é possível notar algumas transformações nos licenciandos, principalmente no que diz respeito à capacidade de se perceber inserido na realidade educacional, com certa autonomia e aprofundamento dos níveis de reflexão. Tais aspectos resultam em relatos de atitudes conscientes da demanda e da qualificação que precisam ter para a tomada de decisões quanto à vida profissional. Aparecem de maneira mais clara questões acerca da gestão da sala de aula, do relacionamento com os alunos e de como adaptar os conhecimentos às necessidades que identificam.

Buscando seguir com essa formação reflexiva, aprimorada - segundo acreditamos -, com o uso da escrita, no Estágio III, fazemos a indicação de que os licenciados privilegiem, em suas narrativas, a descrição do planejamento, da organização da aula e de aspectos relevantes relacionados à sua atuação. Trazemos alguns excertos das narrativas dos mesmos alunos em formação.

Nessa parte deste relatório, mais conhecido como conclusão, eu decidi mudar o meu nome, pois acredito que nada está concluído, mas sim está em constante transformação, pois eu co- 
mecei dizendo que não queria ser professor, mas estou terminando dizendo que quero seguir nessa área. [licenciando 1, narrativa produzida em: 11/2017]

Talvez eu tenha me esquecido de mencionar, mas que alegria poder ligar ou chegar à escola e as pessoas me chamarem de professor! [licenciando 1, narrativa produzida em: 11/2017]

Este espírito desacomodado é importante e necessário para que eu, atento a tudo que acontece ao meu redor, eu possa por em cheque a minha própria formação, ou seja, enxergar as possiveis conexões (e desconexões) entre a bagagem teórica que construí ao longo do curso e as demandas reais da sala de aula. Lançar um olhar crítico à minha formação e discutir até que ponto ela se mantém sólida e abrangente diante dessas demandas é o principal objetivo a que me proponho. [licenciando 2, narrativa produzida em: 11/2018]

$\mathrm{Na}$ narrativa do licenciando 1, sobre o desejo de mudança (REIS, 2008), ele registra sua decisão de "mudar o nome" nessa terceira etapa, destacando sua percepção de que tudo está em transformação, num movimento contínuo que não se encerra. Ele observa sua própria transformação, ao longo curso, de maneira especial no que diz respeito à postura de alguém que não queria ser professor e que agora sente que deseja sim a docência como profissão e que se sente feliz de ser reconhecido como professor.

A narrativa do licenciando 2 também coloca em destaque a dimensão relativa à tomada de consciência do que sabe e do que necessita aprender (REIS, 2008). Ele ainda reflete sobre as articulações entre o que estuda e vivencia na universidade com a experiência na escola básica e se questiona se efetivamente essa formação contribui para enfrentar os desafios da profissão que escolheu, a docência em matemática.

Nesta fase, os licenciandos apresentam, em suas narrativas, um nível de conhecimen- to prático acentuado e um reconhecimento do seu papel como professor. Os relatos pessoais destacam as experiências formativas e as reflexões que fazem sobre si mesmos, sobre a qualidade da sua formação e sobre o seu papel profissional. Colocam em perspectiva suas lembranças, experiências rememoradas e atuais, sua atuação prática, suas reflexões de maneira mais aprofundada e já esboçam ações futuras delineando um caminho como profissionais da educação e projetando de forma consciente o professor que desejam ser.

\section{Algumas Considerações}

Ainda que para os alunos do curso de Matemática pese o fato de se tratar de um trabalho de conclusão de semestre, momento de muitas provas e entregas de trabalho, e com o agravante de que a escrita ainda é desconfortável para muitos deles, a proposta de produção de narrativas como um relatório escrito - reflexivo -, que integra parte da avaliação dos estudantes, tem-se mostrado como um recurso importante para a discussão sobre a profissão docente.

As narrativas expressam os dilemas e as angústias com o trabalho e a realidade escolar com as quais se deparam nos estágios e a reafirmação do desejo de ser professor, a tomada de consciência do seu preparo acadêmico e a transição de sua condição de aluno para o responsável pelo trabalho em sala de aula. Essa tomada de consciência, essa dualidade, esse reverso de posições e diferentes atuações é o que mais temos presente na maioria das narrativas. Mas é também o que encontramos de mais criativo e provocador nesta proposta, a da escrita narrativa - uma vez que abre o debate para as experiências individuais e coletivas a que damos espaço, com a socialização das atividades, e para o compartilhamento desses saberes que buscam valorizar o processo de formação e desenvolvimento pessoal. 
As experiências vividas, a rememoração de imagens e vivências de outro tempo permitem conectar dimensões pessoais esquecidas, mas que, ao serem acessadas e recuperadas, ganham novos significados e podem ser situadas num tempo que entrecruza cenários e significações.

As questões que emergem com os relatos dos envolvidos nesse processo de formação, e que são postas em discussão ao final de cada semestre, nos fazem acreditar que a construção de narrativas tem se revelado como uma estratégia muito eficaz e potente para o exercício da observação, da escuta, da consciência do choque de realidade na transição de aluno para professor, das necessidades de novas ações pedagógicas, da emergência de uma mudança de concepções e adequação de postura, do sentimento de pertencimento e da capacidade de entender-se como professor, como profissional.

A escrita de narrativas reflexivas também é um importante recurso para o pensar e o lidar com o inesperado da profissão, acessando uma multiplicidade de ações que são vivenciadas, discutidas e registradas, ao longo da trajetória formativa. Muito provavelmente essas reflexões serão relembradas em outros momentos e darão suporte a ações, fundamentando um comportamento íntegro e de responsabilidade social.

Por outro lado, também oportuniza ao professor formador o conhecimento de seus alunos em formação, o repensar sobre como vivenciam suas experiências formativas, o que priorizam, quais as suas reais necessidades e a possibilidade de investir em novas propostas formativas.

Os licenciados, ao narrarem sua história e as experiências formativas que vivenciam, buscam em suas memórias os fatos que destacam como os que representam as experiências que os marcaram, as relações com os grupos que provocaram reflexões e redirecionamentos e, dessa maneira, reconstituem suas vivências, seu tempo, seus entendimentos, sua cultura, suas concepções e suas histórias. Ao relembrarem e escreverem suas trajetórias, contam, recontam ... escrevem as suas histórias.

\section{Referências}

ABRAHÃO, Maria Helena Menna Barreto. Memoriais de formação: a (re)significação das imagens-lembranças/recordações-referências para a pedagoga em formação. Educação, Porto Alegre, v. 34, n. 2, p. 165-172, mai./ago. 2011.

BRASIL. Parâmetros Curriculares Nacionais: Matemática. Brasília, DF: MEC; SEF, 1998.

Lei no 9.394, de 20 de dezembro de 1996. Estabelece as diretrizes e bases da educação nacional. Diário Oficial da União, Brasília, 23 dez. 1996. Disponivel em: <http://www.planalto.gov.br/ccivil_03/LEIS/L9394compilado.htm>. Acesso em: 24 dez. 2018.

Conselho Nacional de Educação. Parecer CNE/CES 1.302/2001. Diretrizes curriculares nacionais para os cursos de matemática, bacharelado e licenciatura. Diário Oficial da União, Brasília, 05 mar. 2002a, Seção 1, p. 15. Disponível em: <http:/ / portal. mec.gov.br/cne/arquivos/pdf/CES13022.pdf>. Acesso em: 24 dez. 2018.

Parecer CNE/CP 9/2001. Diretrizes curriculares nacionais para a formação de professores da educação básica, em nível superior, curso de licenciatura, de graduação plena. Diário Oficial da União, Brasília, 18 jan. 2002b, Seção 1, p. 31. Disponível em: <http://portal.mec.gov.br/cne/arquivos/pdf/009. pdf>. Acesso em: 24 dez. 2018.

Resolução no 02/CP/CNE/2015. Define as Diretrizes Curriculares Nacionais para a formação inicial em nível superior (cursos de licenciatura, cursos de formação pedagógica para graduados e cursos de segunda licenciatura) e para a formação continuada. Brasília, DF: CP; CNE; MEC, 2015.

CLANDININ, Jean; CONNEllY, F. Michael. Pesquisa 
narrativa: experiências e história em pesquisa qualitativa. Tradução do Grupo de Pesquisa Narrativa e Educação de Professores ILEEL/UFU. Uberlândia, MG: EDUFU, 2011.

FERRAROTTI, Franco. Sobre a autonomia do método biográfico. In: NÓVOA, António; FINGER, Matthias. (Orgs.). 0 método (auto)biográfico e a formação. Lisboa: Ministério da Saúde; Departamento de Recursos Humanos da Saúde; Centro de Formação e Aperfeiçoamento Profissional, 1988. p. 17-34.

FREITAS, Maria Tereza Menezes. A escrita no processo de formação contínua do professor de matemática. 2006. 300 f. Tese (Doutorado em Educação) Faculdade de Educação, Universidade Estadual de Campinas, Campinas, SP, 2006.

FREITAS, Liliane Miranda; GHEDIN, Evandro Luiz. Narrativas de formação: origens, significados e usos na pesquisa-formação de professores. Revista Contemporânea de Educação, v. 10, n. 19, p. 111-13, jan./ jun. 2015.

IMBERNÓN, Francisco. Formação docente e profissional: formar-se para a mudança e a incerteza. 9. ed. São Paulo: Cortez, 2011. v. 14.

MARCELO, Carlos. Desenvolvimento profissional docente: passado e futuro. Revista de Ciências da Educação, n. 8, p. 7-22, jan./abr. 2009.

NÓVOA, António. Formação de professores e profissão docente. In: Os professores e sua formação. 2. ed. Lisboa: Dom Quixote, 1995. p. 13-33.

NÓVOA, António. Os professores e as histórias de sua vida. In: Vidas de professores. Porto: Porto Editora, 2000. p. 11-30. (Coleção Ciências da Educação, 4).
OLIVEIRA, Rosa Maria Moraes Anunciato. Narrativas: contribuições para a formação de professores, para as práticas pedagógicas e para a pesquisa em educação. Cuiabá. Revista de Educação Pública, Cuiabá, v. 20, n. 43, p. 289-305, mai./ago. 2011. Disponível em: <http://periodicoscientificos.ufmt.br/ojs/index. php/educacaopublica/article/view/307>. Acesso em 26 dez. 2018.

REIS, Pedro Rocha dos. As narrativas na formação de professores e na investigação em educação. Nuances: Estudos sobre Educação, Presidente Prudente, ano XIV, v. 15, n. 16, p. 17-34, jan./dez. 2008. Disponível em: <http://www.scribd.com/doc/12655950/Asnarrativas-na-formação-de-professores-e-na-investigação-em-educacao>. Acesso em: 26 dez. 2018.

RICHIT, Adriana; ALBERTI, Luana Angélica. Tendências no ensino da matemática nos anos finais do ensino fundamental: abordagens evidenciadas em livros didáticos. REVEMAT, Florianópolis, v. 12, n. 1, p. 152-172, 2017.

ROLDÃO, Maria do Céu. Função docente: natureza e construção do conhecimento profissional. Revista Brasileira de Educação, v. 12, n. 34, p. 94-181, jan./ abr. 2007.

SERRAZINA, Maria de Lurdes Marquês. Conhecimento matemático para ensinar: papel da planificação e da reflexão na formação de professores. Revista Eletrônica de Educação, v. 6, n. 1, mai. 2012. Disponível em: <http://www.reveduc.ufscar.br/index.php/ reveduc/article/view/355/162>. Acesso em: 29 mar. 2019.

Recebido em: 10.01.2019

Aprovado em: 27.01.2019

Maria das Graças dos Santos Abreu é Mestre em Educação pela Universidade Federal de São Carlos e doutoranda em Educação pelo PPGE da Pontificia Universidade Católica de Campinas. Professora da PUCCampinas nos cursos de Matemática e Pedagogia. Grupo de Pesquisa: Formação de Professores e Práticas Pedagógicas. e-mail: maria.abreu@puc-campinas.edu.br

Rua Professor Luis Cassiano da Silva, 181 - Jardim Conceição-Campinas/SP - CEP: 13091-040 - Telefones: (19) 997158787 e (19)32073181 
Maria Auxiliadora Bueno de Andrade Megid é Mestra e Doutora em Educação - Educação Matemática pela Unicamp. Professora da Faculdade de Educação da Pontificia Universidade Católica de Campinas - Coordenadora do Programa de Pós-Graduação em Educação PUC-Campinas. Grupo de Pesquisa: Formação de Professores e Práticas Pedagógicas. E-mail: dmegid@puc-campinas.edu.br

Av. Alaor Faria de Barros, 1050, Bl. 1 ap. 164. Bairro Vila Alphaville. Campinas/SP - CEP: 13.098-393 - Telefones: (19)992998642 e (19)31437409

Alessandra Rodrigues de Almeida é Mestre em Psicologia pela Universidade São Francisco e Doutora em Ensino de Ciências e Matemática pelo PECIM Unicamp. Professora da Faculdade de Educação da Pontificia Universidade Católica de Campinas e Professora Colaboradora da Unicamp vinculadas aos Programas PECIM e Mestrado Profissional - Grupo de pesquisa: CIEspMat - Conhecimento Interpretativo e Especializado do Professor que Ensina Matemática. E-mail: alessandra.almeida@puc-campinas.edu.br

Rua Maria Monteiro de Merlo, 91 - Parque Modelo. Amparo/SP - CEP 13.905-525 - Telefones: (19)996729393 e (19)38173579 